\title{
Have the Modal Verb Phrase Structures Been Well Presented in Malaysian English Language Textbooks?
}

\author{
Laleh Khojasteh (Corresponding author) \\ Department of Foreign Languages, Shiraz Branch, Islamic Azad University, Shiraz, Iran \\ Tel: 60-123-804-248Ｅ-mail: khojastehlaleh@yahoo.com \\ Reza Kafipour \\ Department of Foreign Languages, Shiraz Branch, Islamic Azad University, Shiraz, Iran \\ Tel: 98-917-315-8394 E-mail: rezakafipour@gmail.com
}

Received: October 21, 2011

Accepted: November 9, 2011

Published: March 1, 2012

doi:10.5539/ells.v2n1p35

URL: http://dx.doi.org/10.5539/ells.v2n1p35

\begin{abstract}
To date, many studies focused on the behavior of English grammatical structures in various national and international textbooks and questioned the authenticity of the language and the grammar presented in these textbooks. To see if Malaysian English language textbooks are free from these issues, this study compared the ways in which modal verb phrase structures are presented in these textbooks and real language use. This was addressed in one research question and the design applied was qualitative content corpus analysis. The findings reveal that evidently, there are very great differences in the relative frequency of use of the nine verb phrase structures in which modals can occur in real language and the ones in Malaysian English language textbooks (Form 1-5). The survey result also reveals that secondary learners are not really exposed to other verb structures, particularly structures with passive, progressive and perfect aspects.
\end{abstract}

Keywords: Modal verb phrase structures, English Grammatical structures, Real language use, Grammar teaching

\section{Introduction}

It has been noted by many grammarians and applied linguistic researchers that modal auxiliary verbs count among one of the most grammatical trouble makers for second and foreign language learners and teachers. For instance, Palmer (1974) notes that the complexity of modal auxiliary verb forms and their semantic functions cannot be compared with any other grammatical structures. Several other researchers highlighted the difficulties ESL and EFL learners usually have in handling this grammar feature (Celce-Murcia \& Larsen Freeman, 1999; Decapua, 2008; Manaf, 2007). However, it has been argued that although lack of grammatical equivalence between learners' target language and first might cause a great challenge for them to produce a particular language structure, lack of fit between descriptions of language phenomena in textbooks and real communication situations may play a greater role in this deficiency (Romer, 2005).

To date, many studies questioned the authenticity of the language, grammar, pragmatics and vocabulary and phraseology presented in various national and international textbooks, and strongly noted that if learners were presented with appropriate grammatical structures in line with real language use, they would have encountered fewer difficulties handling relevant structures in communicative situations (Biber, Conrad, Reppen, Byrd and Helt, 2002; Gilmore, 2004; Meunier and Gouverneur, 2009; Romer, 2005, 2004a, 2004b; Nordberg, 2010, Mukundan and Khojasteh, 2011; Vellenga, 2004). Comparing the authenticity, grammar and vocabulary in textbooks and reference corpora such as Longman Spoken and Written English (LSWE) Corpus and British National Corpus (BNC), these studies indeed demonstrate that by ignoring frequent features of the language spoken or written by real language users, many textbooks implicitly portray these linguistic features as monolithic phenomena, which behave in the same way regardless of different contexts and situations of use. As regards to the grammar one good example is Barbieri \& Eckhardt's (2007) study which was based on the comparison of reported speech in seven ESL/EFL grammar textbooks used in Germany and Longman Spoken and Written English (LSWE) Corpus. The findings of their study show that textbooks neglect important information on the use of this structure in real language in general and direct reporting verbs in specific. For example they reported that although in real language use say and tell are 
the most used reporting verbs, EFL textbooks in Germany tend to under represent most additional reported speech other than say and tell. Furthermore, there is a general neglect of information on the tense backshifting rule, register and context-dependent variation. Finally they conclude that the books were not written based on empirical studies because it is not clear which principles informed textbooks authors' decisions about which reporting verbs to present. Likewise, Mukundan and khojasteh (2010) investigated 9 central modal auxiliary verb forms and their verb phrase structures in a pedagogic Corpus in Malaysia and BNC and found a mismatch between the two. The finding reveals that for certain modal auxiliaries; there is a discrepancy between modal frequency order in the textbook corpus and the BNC. For example, when modal could is considered the fourth most common modal in BNC, this modal is standing in the seventh position in the textbook corpus and surprisingly enough could is not even taught implicitly in Malaysian secondary school level.

If such is the case, present-day textbooks might lack a broad empirical foundation which leads us to the first reason for carrying out such a study; because non-empirically-based teaching materials can be increasingly misleading. More often than not, these textbooks may be based on a limited collection of example sentences which are not attested instances of language use but rather intuitive examples which have been invented for the purpose of illustrating a particular point, or which have been taken from earlier linguistic studies and grammar books. In this case, material developers unwittingly miss the quantitative data on the distribution of different modal auxiliary verb forms or functions and on co-occurrences with context features such as common modal verb phrase structures.

By comparing a textbook corpus with reference corpora or real-language corpora, indeed, it is imperative to examine the language to which learners are exposed to in order to develop more effective pedagogical materials for EFL/ESL learners. Having mentioned that, this study does not suggest for EFL/ESL learners to be members of native speaker communities. From corpus linguistics point of view, native speaker corpus is not intended to serve as a language model to be exactly imitated by L2 learners (Gavioli and Aston, 2001). They suggest, however that, reference corpora such as BNC can guide the researchers to identify the mismatch between EFL/ESL materials and native speaker corpus, and can cater for usefulness, difficulty and learnability of certain grammatical structures in these materials. Insights such as high frequent forms from native speaker corpus, from Nation's (2010) view point "give [the language learner] a better return for learning efforts" (p. 1).

Accordingly, since in this study, it is argued that "the verb phrase is one of the most important elements of the sentence" (Mindt, 2000, p. 84), the question was asked in the contextual analysis of modal auxiliary verbs was:

"How extensively are the distributions and the categories of words that colligate with modal auxiliary verbs presented in Forms 1-5 Malaysian English language textbooks in line with their usage in real language use?"

\section{Methodology}

\subsection{Population and Sampling}

For the purpose of this study, the population for the English language corpus was sourced from Malaysian English language textbooks used for secondary Malaysian students of Form 1 through Form 5. The corpus used in this study was compiled by Mukundan and Analeka (2007). This pedagogic corpus consisted of 311,214 running words. This corpus can be classified as a "pedagogic corpus" as it is coined by Willis (1993) and defined by Hunston (2002) as a collection of data that "can consist of all the course books, readers etc. a learner has used" in an ESL/EFL language learning program (p.16). This textbook corpus has been used in many significant corpus-based studies (Menon, 2009; Mukundan\&Roslim, 2009; Mukundan\&Anealka, 2007; Mukundan, 2004; Mukundan\&Khojasteh, 2011), and the results have shed light on the lexical and grammatical structures that the secondary Malaysian students are exposed to in their textbooks.

\subsection{Instrumentation}

The WordSmith Tools Version 4.0 was used almost entirely for the purpose of this research, because it has been recognized as a capable and suitable tool to support quantitative and qualitative data analysis by many researchers (Baker, 2006; Bondi, 2001; De Klerk, 2004; Flowerdew, 2003; Henry \& Roseberry, 2001; Menon, 2009; Mukundan, 2004; Mukundan\&Roslim, 2009; Nelson, 2001; Scott, 2001).

\subsection{Detailed Analysis of Data}

While collocation is instantly identifiable on the vertical axis of an alphabetical concordance, colligation represents a step in abstraction and is therefore less immediately recognizable unless the text is coded with precisely the required grammatical information. Since this corpus was not the annotated corpus, and the aim of this question is to analyze the modal's grammatical forms or constructions, it was essential for us to go through the coding process in order to identify the modal verb phrase structures existing in the textbook corpus. The framework used for this study to identify modal verb phrase structures in this textbook corpus is a combination of structures found by Mindt (1995) 
in a corpus of fiction texts and Kennedy (2002) in the BNC. In the former, Mindt (1995) reported five modal verb phrase structures including 1) modal + bare infinitive, 2) modal + passive infinitive, 3) modal + progressive infinitive, 4) modal + perfective infinitive, 5) modal + perfect passive infinitive. Kennedy (2002) on the other hand, added four more verb phrase structures to Mind's (1995) list including modal alone, modal + be + being + past participle (or adjective), modal + have + been + present participle, and modal + have + been + being + past participle. For this study, it was decided to keep the common structures between the two lists but only add one more structure from Kennedy's (2002) list (modal alone). It was decided not to do a query for the other structures because according to Kennedy (2002, p. 89) these structures are "extremely rare". Another reason that we decided to eliminate these three structures from our list is that Mukundan and Khojasteh (2011) found that there is not even a single instance of these structures in their corpus-based analysis on Form 1, 2 and 3 Malaysian English language textbooks.

Based on the above mentioned structures we coded the occurrence of each modal auxiliary. The reason behind the fact that we did not simply look for the grammatical choices that co-occur with modal auxiliary verbs and conversely doing this based on pre-existing structures is that Hoey, Mahlnerg, Stubbs and Teubert (2007) and Hunston and Francis (2000) suggest studying colligation with making use of existing grammatical terminologies. These terminologies according to Hoeyet al., (2007, p. 35) is the product of "pre-corpus investigations".

These structures plus a code set which was used for this study with a sample example can be seen in below:

1) Modal alone (0) who will go? I will.

2) Modal + infinitive (infin) Sam can swim./ She must be hungry.

3) Modal + be + past participle (be past ptc) It should be replaced.

4) Modal + be + present participle (be presptc) They will be arriving soon.

5) Modal + have + past participle (have ptc) He might have done it.

6) Modal + have + been + past participle (have been past ptc) It should have been fixed.

Apart from the above assigned codes, another code was assigned for "none of the above items" $(\mathrm{N})$ since in the textbook corpus there were incomplete utterances in exercise units that did not provide us with enough span around the node word in order to make them decide what verb phrase structure the modal carries.

After the coding, which in itself was analytical, we undertook several additional steps. These steps, too, were done within the framework of the proposed research question. First, we summarized the findings identified during the coding and then identified and articulated the patterns and relationships among our findings so that we could answer our research question. Then, we related these more involved findings to the results of major corpus-based findings on modal verb phrase structures such as Kennedy's (2002), Mindt (2000) and Mindt (1995). The last step allowed us to put our findings into perspective.

\section{Results}

In order to determine these shares, absolute occurrences for each possible form were retrieved from the database, applying the query strategy explained earlier. Table 1 displays the retrieved absolute numbers of all modals.

In this textbook corpus, constituting the greatest share is the modal plus infinitive (e.g. can go) followed by the modal + be + past participle (e.g. can be cleaned) structure. Conversely, all other forms (modal alone and all perfect and fragmentary forms) are comparatively rare. Out of 1288 frequency occurrences of can, 1,067 (82.8\%) of them occurred in structure 2 and $167(12.96 \%)$ in structure 3, which together account for almost $96 \%$ of all can cases throughout Forms 1 to 5. A similar trend is found for all the other modals without any exceptions, for example, (would, 96\%; could, 94.5\%; will, 92\%; should, 90\%). (1), (2) and (3) are sample sentences for structure 2 from textbook corpus.

Examples: (1) You can interview your family members or friends, or collect articles from the newspapers or the Internet.

(2) Sufian and his friends would like to invite their schoolmates to join them in their project.

(3) You won't regret it!

However, considering passive constructions alone, this structure (e.g. can be used) is only popular for some modals such as can (167 instances), will (81), and should (74) while it is moderately frequent in would with 20 instances, could (19), may (18), must (35). Finally, not frequent at all in this structure are the cases of shall and might with 1 and 3 instances each respectively (see (4) and (5) for sample sentences from the textbook corpus). 
Examples: (4) Some of the words can be used more than once.

(5) Puan Lim will be transferred to a new school next week.

As for modals with progressive aspect (e.g. will be seeing), we can clearly see that this aspect is rather rare for almost all modals throughout the textbooks except for will with 16 instances throughout the Forms $1-5$ textbooks. The paucity of this aspect is more obvious when we look specifically at the distribution of progressive aspect within Forms 1 - 5 textbooks. For instance, there is only one instance of this aspect in Form 1 and Form 5 and only 2 instances in the case of must in Form 4 (see (6) and (7) for sample sentences from textbook corpus).

Examples: (6) At first, the lessons can be confusing but after the whole course, you'll be fine.

(7) Define the scope of your speech - what you will be talking about.

Table 4.5 also shows that modals can, would, could and shall do not have any proportion in the textbook corpus in structure 5 (e.g. may have gone). However, this structure has a minor occurrence in the case of might, may, will and should throughout the textbooks. The most frequent modal marked for this structure is must with 14 instances (see (8) and (9) for sample sentences from textbook corpus).

Examples: (8) I know it must have been hard for my parents but they knew what was best for him.

(9) You may want to include the events that might have happened the day before.

The least common modal verb phrase structure among all is modal alone. Except for modals can and will that was marked for this aspect 6 and 5 times respectively, the rest of the modals did not show enough tendencies for structure 1 (see (10) and (11) for sample sentences from textbook corpus).

Examples: (10) Won't you dance with me? I shouldn't.

(11) Yes, I would.

(4) Is there anything I can do to help? Yes, you can.

Structure 6 is only used once in Form 3 for the modal could. The only sentence found in Form 3 that represents this structure is (14).

Example: (14) My son could have been killed.

Finally, there are certain modals that have been tagged as ' $\mathrm{N}$ ' because they did not follow any of the aforementioned aspects. In some cases such as will with 62 instances, can (47) and must (54) modals did not follow any patterns at all. Examples (12) and (13) are sample sentences from some of these modals.

Examples: (12) How often can ....?

(13) Give suitable responses to these sentences using 'must' or 'must not'.

\section{Summary and Discussion}

The results presented in Table 1 shows that the most used modal verb phrase structures for all modals in textbook corpus is structure 2 (modal + bare infinitive). On the one hand, based on the findings of Kennedy (2002), this study shows a rather one-sided picture being portrayed by Malaysian English language textbooks as regards structure 2 . Kennedy (2002) reported that in BNC, the modal + bare infinitive structure accounts for $76 \%$ of all modal tokens in the corpus, whereas this study shows that the frequency count for this structure has jumped to $81 \%$. On the other hand, this finding matches Mintd's (2000) reported figure for structure 2 that is exactly $81 \%$. Since the discrepancy found between the results for our textbook corpus and BNC is rather marginal, it is slightly unfair to criticize the textbook authors simply on the basis of their treatment of structure 2. However, it is important to discuss further these results based on the extent which each individual modal contributes to each structure. In that case, for example, we can see that there is a mismatch between the shares each modal has for structure 2 in the results compared with real language use. Mindt (2000) and Kennedy (2002) reported that the most used modal in structure 2 is will followed by can, would, could, may, should and shall. However, the results of this study show that can with 1,067 instances outweighs that of will (773) and should (373) exceed would (370) and may (285). It is also worth mentioning that must with $5.72 \%$ frequency occurrences have been definitely overused in this structure throughout the textbooks because must with this pattern (less than 2.9\%) did not even appear among other ranked modals in Mindt's (2000, p. 589) table. A tentative explanation for this bias is that proportionally can is the most frequently modal used in textbook corpus while this modal stands in the third place in BNC. Indeed, since Mukundan and Khojasteh (2011) came to the conclusion that the frequency and rank order of modal auxiliary verbs found in the English language textbooks used in Forms 1-5 are not empirically based, the consequences in terms of the weight given to each modal verb phrase structure are hardly surprising. Would for example, the second most frequent modal 
auxiliary in all major corpora, stands also second (78.8\%) in terms of structure 2 according to Kennedy (2002). Similarly, would standing in fourth place in terms of overall frequency occurrences in Malaysian English textbooks, occupies the same place (fourth) in terms of structure 2 in textbook corpus.

Regarding structure 3, Kennedy (2002) reported that in BNC can is the most frequently-occurring modal (27.2\%) followed by may (19.1\%), will (18.1\%), should (13.7\%) and could (10.7\%). The finding from this pedagogic corpus is in line with the one in Kennedy's (2002) except for the modal may which was not given enough emphasis by textbook writers with its rare occurrences throughout Forms 1 to 5 .

As it can be seen in Table 1, structure 4 is only used for will with 16 instances throughout Form 1 to 5 textbooks. This structure is notably rare in the case of the rest of the modals with for example should getting 6 hits and can with only 2 hits. When this result is compared with the frequency occurrences reported by Kennedy (2002), it is found that this structure has been under-presented in Malaysian textbooks. This structure is highly used by will with $41.3 \%$ and would $(20 \%)$ in BNC, whereas in textbook corpus it is only used $1.7 \%$ and $0.25 \%$ respectively. Likewise, structure 5 does not have high use in any of the Forms $1-5$ textbooks. For some modals such as can, would, could and shall there are zero instances of this structure which leads us to conclude that structure 5 is underused in Malaysian English language textbooks. Following structures 2 and 3, structure 5 is the most frequently used structure by native speakers (Kennedy, 2002). Specifically, would (37\%) has the highest proportion in this structure followed by the modal will in BNC (Kennedy, 2002). However, as it can be seen in Table 1, the results show that this structure did not even occur once for would in textbook corpus. This shows how textbook writers have ignored such insights from corpus-based analysis. This structure, Kennedy (2002, p. 89) posits, should be given "high priority" in language pedagogy.

For structure 1 (modal alone) we can also see that except for can (6 instances), will (5) and would (3) with their insignificant frequency occurrences throughout the textbooks, the rest of the modals show zero frequency towards this structure. In terms of popularity of this structure among all nine central modals, Kennedy (2002) reported that $83 \%$ of the modal tokens come from can, will, would and could. In terms of learnability, like structure 3, it possibly means that Malaysian learners may have difficulty learning this structure when it is not even featured in their textbooks explicitly. Lack of proper understanding of this structure for Malaysian learners, perhaps create difficulties in producing it in spoken negative contexts because this structure accounts for $14 \%$ of the modal tokens in the aforementioned context (Kennedy, 2002). As Conrad (2000) posits, having important discourse functions in particular registers, is a very good reason for textbook writers to consult corpus linguistics in terms of descriptions and frequency information.

Structure 6 is the only structure that showed the lowest frequency occurrences for all modals. Surprisingly, there is only 1 instance in terms of modal could in the Form 3 textbook. However, considering the fact that this structure is not really frequent in the BNC (Kennedy, 2002), it is perhaps understandable why textbook writers did not give any share to this particular structure in Malaysian textbooks.

Finally, it is important to note that except for structure 2, none of the above mentioned structures has been taught to students in any of the Forms from 1 to 5 to inform Malaysian students about their semantic and pragmatic information. This perhaps is one of the main reasons that Malaysian learners avoid the use other structures such as modal + perfect infinitive and modal + progressive infinitive in their essays according to Manaf (2007). Although Manaf (2007) failed to report on the use of structures 3 and 4 by Malaysian students in EMAS corpus, but from the 47 examples she has provided in terms of syntactically accurate and inaccurate modal verb phrase structures, we can clearly see that none of these examples portray the use of structures 3 and 4 in Malaysian students' essays. If these structures are not taught, Decapua (2008, p. 213) believes, "a great deal of information that is not necessarily immediately obvious to students" will go unnoticed by ESL/EFL learners. In addition to that, as part of the consciousness-raising for teachers, Kennedy (2002) believes the analysis of modal verbs in corpus-derived data should be integrated in language education "not just because they exist, but because they are used often enough to justify inclusion in instruction" (p. 89).

\section{Conclusion}

Apart from many criteria proposed for principled selection of syllabus designs, frequency and range have been highly recommended (Kennedy, 2002; Koprowski, 2005; Mindt, 2000; Romer, 2004a; Sinclair, 1991 and many more). Nation and Waring (1997, p.17) state that applying frequency information in textbooks ensures that students are exposed to the language they most probably meet again outside the classroom walls. Likewise, Romer (2004a, p.152) believes we should always make sure that the language students are exposed to in their textbooks is as close as possible to the language they will likely to be confronted with in natural communicative situations. However, evidently, there are very great differences in the relative frequency of use of the nine verb phrase structures in which modals can occur 
in real language and the ones in Malaysian English language textbooks (Form 1-5). For example, despite the fact that will is the most frequently used modal in structure 2 (modal + infinitive) in real language use, in textbook data can is predominantly used in this structure. The survey result also reveals that secondary learners are not really exposed to other verb structures, particularly structures with passive, progressive and perfect aspects. Perhaps that would be one of the reasons why Rosli and Edwin (1989) in their study of errors in Form 4 student compositions found that verb forms and the verb aspects of modals are the most problematic for Malaysian learners. According to Kennedy (2002), the above mentioned structures including structure 1 (modal alone) should take priority in language pedagogy. Accordingly, explicit teaching of these structures is highly recommended in Malaysian English textbooks in order for students to differentiate between the verb forms used in each. This, in turn, Manaf (2007) suggests, will help Malaysian students to have a better understanding of the structures used particularly in writing.From 1 to Form 5 Malaysian English textbooks indeed enjoy many positive features; their coverage of modal verb phrase structures is only a small part of the books. However, the most salient facts reflected from natural language corpora should not be ignored in the textbooks.

\section{References}

Barbieri, F., \& Eckhardt, S. (2007). Applying corpus-based findings to form-focused instruction: The case of reported speech. Language Teaching Research, 1(3), 319-346. http://dx.doi.org/10.1177/1362168807077563

Baker, P. (2006). Using Corpora in Discourse Analysis. London: Continuum.

Biber, D., S. Conrad, R. Reppen, P. Byrd, and M. Helt. (2002). Speaking and writing in the university: A multi-dimensional comparison. TESOL Quarterly, 36, 9-48

Bondi, M. (2001). Small corpora and language variation: Reflexivity across genres. In M. Ghadessy, A. Henry, \& R. Roseberry (Eds.), Small corpus studies and ELT (pp. 135-174). Amsterdam/ Philadelphia: John Benjamons Co.

Celce-Murcia, M., \& Larsen-Freeman, D. (1999). The Grammar book: an ESL/EFL teacher's course. $2^{\text {nd }}$ ed. Boston: Heinle\&Heinle.

Decapua, A. (2008). Grammar for teachers: A Guide to American English for Native and Non-Native Speakers. New Rochelle: Springer.

De Klerk, V. (2004). The use of 'actually' in spoken Xhosa English: A corpus study. World Englishes, 24(3), 275-288. http://dx.doi.org/10.1111/j.0883-2919.2005.00410.x

Flowerdew, L. (2003). A combined corpus and systematic-functional analysis of the problem solution pattern in a student and professional corpus of technical writing. TESOL Quarterly, 37(3), 489-511. http://dx.doi.org/10.2307/3588401

Gavioli, L., \& Aston, G. (2001). Enriching reality: Language corpora in language pedagogy. ELT Journal, 55(3), 238-246. http://dx.doi.org/10.1093/elt/55.3.238

Gilmore, A. (2004). A comparison of textbook and authentic interactions. ELT Journal 58(4), 363-71. http://dx.doi.org/10.1093/elt/58.4.363

Henry, A., \& Roseberry, R. L. (2001). Using a small corpus to obtain data for teaching a genre. In M. Ghadessy, A. Henry, \& R. Roseberry (Eds.), Small corpus studies and ELT (pp. 93-113). Amsterdam/ Philadelphia: John Benjamons Co.

Hoey, M., Mahlnerg, M., Stubbs, M., \& Teubert, W. (2007). Text, discourse and corpora: Theory and analysis. London: Continuum.

Hunston, S., \& Francis, G. (2000). Pattern Grammar. A Corpus-driven Approach to the Lexical Grammar of English. Amsterdam: John Benjamins.

Hunston, S. (2002). Corpora in applied linguistics. Cambridge, England: Cambridge University Press.

Koprowski, M. (2005). Investigating the usefulness of lexical phrases in contemporary coursebooks. ELT Journal, 59(4), 322-332. http://dx.doi.org/10.1093/elt/cci061

Meunier, F., \& Gouverneur, C. (2009). New types of corpora for new educational challenges. In K. Aijmer (Ed.), Corpora and language teaching (pp.179-201). Amsterdam: John Benjamins.

Mindt, D. (1995). An Empirical Grammar of the English Verb: Modal Verbs. Berlin: Cornelsen.

Mindt, D. (2000). An Empirical Grammar of the English Verb System. Berlin: Cornelsen.

Mukundan, J. (2004). A Composite Framework for ESL Textbook Evaluation. PhD Thesis. Universiti Putra Malaysia. 
Mukundan, J., \& Anealka, A. H. (2007). A forensic study of vocabulary load and distribution in five Malaysian Secondary School Textbooks (Forms 1-5). Pertanika Journal of Social Science and Humanities, 15(2), 59-74

Mukundan, J., \& Khojasteh, L. (2011). Modal Auxiliary Verbs in Prescribed Malaysian English Textbooks. English Language Teaching, 4(1), 79-89

Mukundan, J., \& Roslim, N. (2009). Textbook Representation of Prepositions. English Language Teaching, 2(4), 123-130

Nation, I. S. P., \& Macalister, J. (2010). Language Curriculum Design. New York: Routledge.

Nation, P., \& R. Waring.(1997). Vocabulary size, text coverage and word lists. In N. Schmitt, and M. McCarthy (Eds), Vocabulary: Description, Acquisition and Pedagogy (pp. 6-19). Cambridge: Cambridge University Press.

Nelson, M. (2001). A corpus based study of business English and business teaching. Oxford: Oxford University Press.

Neuendorf, K. A. (2002). The content analysis guidebook. Thousand Oaks, California: Sage Publications.

Nordberg, T. (2010). Modality as portrayed in Finish upper secondary school EFL textbooks: A corpus-based approach. Master's Thesis. University of Helsinki. [Online] Available: https://helda.helsinki.fi/handle/10138/19357

Palmer, F. R. (1974). The English verb. London: Longman.

Romer, U. (2004a). A corpus-driven approach to modal auxiliaries and their didactics. In J. Sinclair (Ed), How to Use Corpora in Language Teaching (pp. 185-199). Amsterdam: John Benjamins.

Romer, U. (2004b). Comparing real and ideal language learner input: the use of an EFL textbook corpus in corpus linguistics and language teaching. In G. Aston, S, Bernardini, \& D, Stewart (Eds.), Corpora and Language Learners (pp. 151-168). Amsterdam: John Benjamins.

Romer, U. (2005). Progressives, patterns, pedagogy. A Corpus-driven Approach to English Progressive Forms, Functions, Contexts and Didactics. Amsterdam: John Benjamins.

Rosli, T., \& Edwin, M. (1989). Error analysis of Form Four English compositions. The English Teacher, XVIII, $110-124$

Sinclair, J. M. (1991). Corpus, Concordance and Collocation. Oxford: Oxford University Press.

Scott, M. (2001). Comparing corpora and identifying key words, collocations and frequency distributions through WordSmith Tolls suite of computer programs. In M. Ghadessy, A. Henry, \& R. L. Roseberry (Eds.), Small Corpus Studies and ELT (pp. 47-67). Amsterdam / Philadelphia: John Benjamins Publishing Co.

Willis, D. (1993). Syllabus, corpus and data-driven learning. IATEFL Conference Report: Plenaries.

Table 1. Verb-phrase Structures of Modals in Form 1-5 Textbooks

\begin{tabular}{cccccccccc}
\hline $\begin{array}{c}\text { Modal } \\
\text { Structures }\end{array}$ & Can & Could & Will & Would & Should & Shall & May & Might & Must \\
\hline S1 & 6 & - & 5 & 3 & - & - & - & - & - \\
\hline S2 & 1067 & 207 & 775 & 370 & 373 & 17 & 285 & 49 & 238 \\
\hline S3 & 167 & 19 & 79 & 20 & 72 & 1 & 18 & 3 & 35 \\
\hline S4 & 2 & 3 & 16 & 1 & 6 & 1 & 2 & 1 & 2 \\
\hline S5 & - & - & 1 & - & 6 & - & 5 & 5 & 14 \\
\hline S6 & - & 1 & - & - & - & - & - & - & - \\
\hline $\begin{array}{c}\text { None of the } \\
\text { above }\end{array}$ & 8 & 10 & 62 & 6 & 36 & 3 & 34 & 28 & 54 \\
\hline
\end{tabular}

